\title{
SEÇÃO
}

RESENHAS 
Até que tenhamos coragem de reconhecer crueldade pelo que ela é - seja a vítima um animal humano ou não humano - não podemos esperar que as coisas melhorem neste mundo... não podemos ter paz vivendo entre homens cujos corações se deleitam em matar criaturas vivas. Para cada ato que glorifica o prazer de matar, estamos atrasando o progresso da humanidade.

Rachel Carson

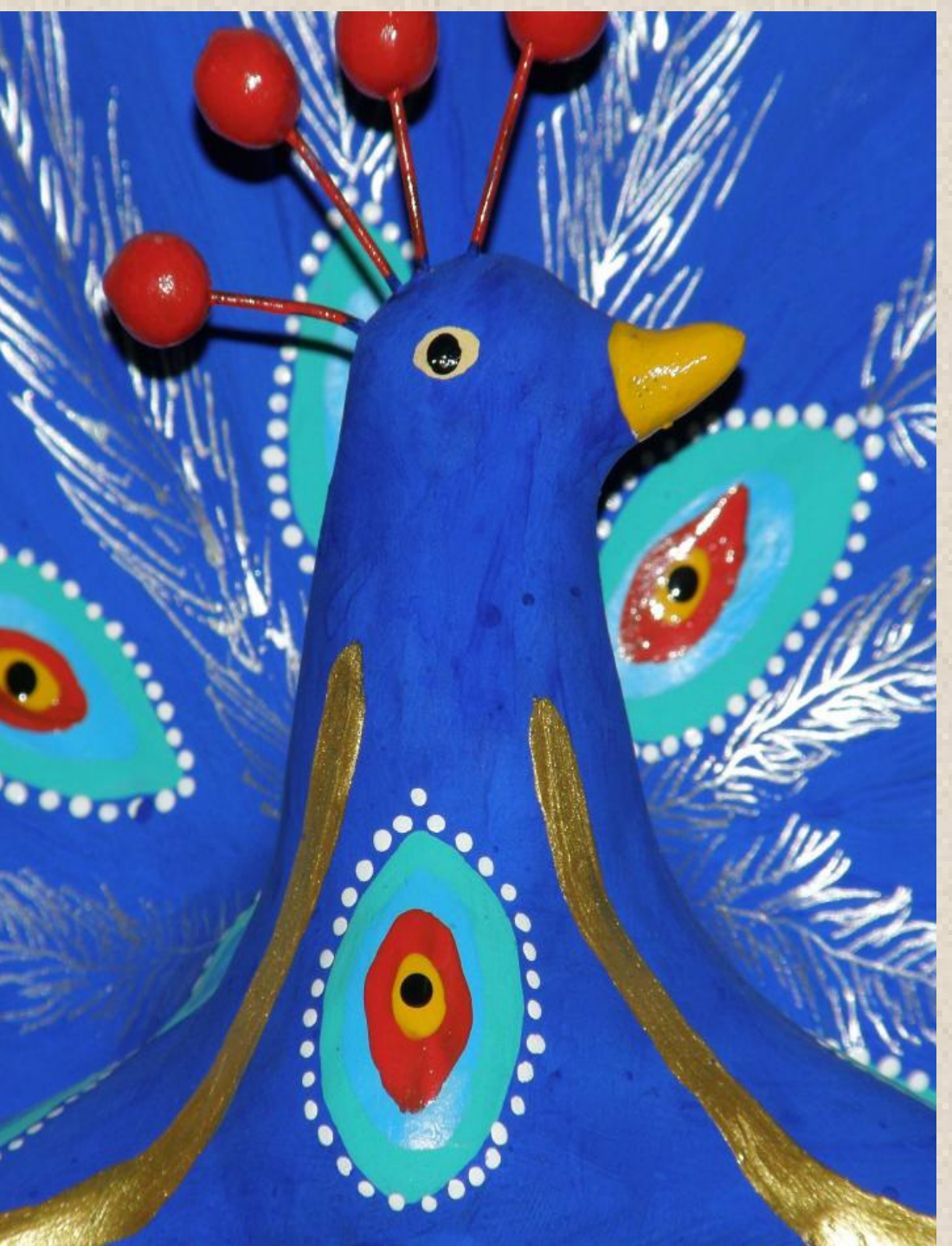




\section{Governança e regimes internacionais: desafios contemporâneos e enfoques teóricos}

\section{Fernanda Sola}

\section{Gonçalves, Alcindo; Costa, José Augusto Fontoura. Governança global e regimes} internacionais. São Paulo: Almedina, 2011.

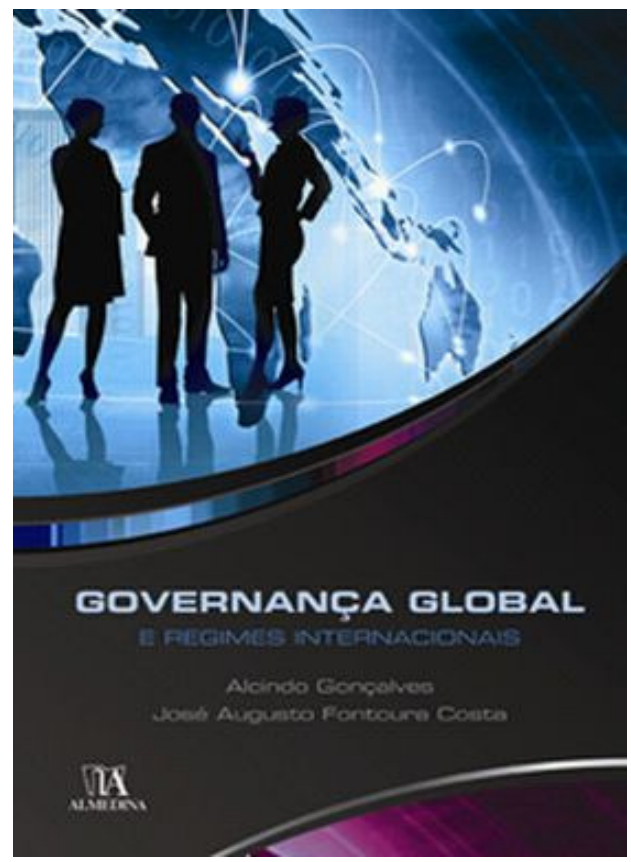

A tradicional casa editorial portuguesa Almedina, dando continuidade a busca de maior participação no mercado brasileiro, lançou o interessantíssimo livro Governança Global e Regimes Internacionais, de autoria de Alcindo Gonçalves - professor do Mestrado e Doutorado em Direito da Universidade Católica de Santos - e José Augusto Fontoura Costa - professor do Departamento de Direito Internacional da Faculdade de Direito da Universidade de São Paulo.

Partindo da necessidade de sistematizar e apresentar as bases teóricas do estabelecimento de formas de gerenciamento de questões internacionais, assim como suas bases jurídicas e institucionais, os autores empreenderam a ousada e fundamental tarefa de discutir os fundamentos jurídicos, políticos e econômicos do tratamento integrado de problemas e alternativas que se tornaram internacionais e globais.

Decerto, já não existe aspecto da vida que não se relacione, mesmo que indiretamente, com alguma norma ou padrão estabelecido internacionalmente. Só de se mencionar as questões ambientais e o ecoturismo são, decerto, inúmeras as questões que se apresentam em um amplíssimo espectro que se espraia da liberalização internacional dos serviços no Acordo Geral sobre o Comércio de Serviços da OMC (GATS) à possibilidade de financiar a manutenção dos ecossistemas e da biodiversidade a partir da atividade turística.

Basta examinar, rapidamente, nossos arredores e nossas últimas atividades atentamente para perceber uma verdadeira miríade de elementos da vida vinculados, de uma ou outra maneira, à internacionalidade. Isso é, normalmente, apresentado como uma consequência de um fenômeno amplo, apelidado de globalização. Com seu toque de Midas, ela aparece como uma explicação universalmente aceita e que apazigua os ânimos analíticos de seus mais dedicados acólitos, bem como de seus detratores e descontentes. 
Como tudo que se converte em uma mesma matéria, mesmo que áurea, tais explicações favorecem a banalização e providenciam o realinhamento das questões em termos de um discurso geral e amplamente aceito. Assim, para retomar um de nossos exemplos, o emprego do ecoturismo para favorecer o uso sustentável da paisagem e das biotas será, por uns, visto como uma excelente oportunidade, alavancada pelos fluxos globais de dinheiro e informações, enquanto os outros criticarão a absorção dos valores pelo mercado e a homogeneização cultural decorrente da comoditização da natureza. Como peças de um jogo de montar, tais topoi podem ser aplicados a virtualmente qualquer objeto, construindo um mesmo discurso que se mimetiza a (e em) si próprio, de modo a reproduzir sua profunda banalidade como se fosse nova, significativa ou crítica.

O livro, partindo de uma cuidadosa e detalhada discussão do estado da arte, ousa por superar tais lugares comuns com muita tranquilidade. $O$ foco nas efetivas dificuldades envolvidas na articulação da governança, bem como na criação, transformação e continuidade dos regimes internacionais ajuda o leitor interessado em qualquer temática global a encontrar subsídios para sua reflexão. Destarte, o presente livro se apresenta como um recurso fundamental para discutir de modo claro e consistente a maneira como tais instituições e regras se formam e passam a influenciar comportamentos.

Conceitos como governança global e regimes internacionais se firmaram, nas últimas décadas, como centrais para o entendimento dos aspectos institucionais tanto do agir internacional, compreendido como aquele que se dá entre Estados, quanto do global, ou seja, o que se realiza em âmbitos locais e mundial, para os quais as fronteiras já não têm mais tanta importância, e envolve uma gama mais ampla de atores, como empresas, organizações da sociedade civil e entidades públicas sub-estatais. É, porém, próprio de noções recentes e influentes o caráter polêmico e a dificuldade de estabelecer definições demasiado sintéticas e que sejam incapazes de refletir sua complexidade.

As realidades internacional e global, com as quais se busca lidar mediante governança e regimes, se recusam a ser corretamente descritas nos termos estreitos das construções teóricas que vêm compondo a corrente dominante do Direito internacional e das Relações Internacionais há muitas décadas: o positivismo voluntarista e o realismo, respectivamente. Na medida em que demandas sociais, políticas e econômicas se põem concretamente e não podem ser atendidas adequadamente a partir da orientação dada por arcabouços epistêmicos cuja conformação já não oferece suficiente correção para a miopia dos tomadores de decisão, surgem soluções que desafiam as balizas teóricas e parecem amalucadas ou heréticas aos olhos mais viciados e envelhecidos. Eppur si muove.

Nesse sentido, o livro busca desvelar um panorama teórico adequado às novas condições e percepções práticas da realidade. Para tanto, embora privilegie a perspectiva das Relações Internacionais com foco na institucionalização, lança mão de uma abordagem multidisciplinar que abrange noções da Teoria do Direito, da Sociologia e Ciência Política. Decerto, vale alertar desde logo, os próprios estatutos epistemológicos de tais ramos do conhecimento estão longe de se expressarem em termos inequívocos e abrigam importantes e intrincados dissensos. Não obstante, se obteve unidade a partir da coesão em torno do problema referente a como se criam e gerenciam organizações e instituições internacionais e globais capazes de estabilizar comportamentos e expectativas.

Trata-se, assim, de discutir e apresentar teorias, mas sempre com muita atenção 
às efetivas necessidades práticas. Como fica muito bem expresso na parte referente à governança ambiental global, a atual e bem construída discussão teórica proposta pelos autores está muito longe de ser bizantina. Com efeito, a melhor leitura do presente texto que pode ser feita é aquela que traz subjacente a preocupação com uma questão internacional concreta cuja solução pode passar por formas organizacionais e jurídicas, clássicas ou não.

Deste modo, a exposição de diversas abordagens relevantes é feita para que estejam coerentemente atadas a partir das reflexões referentes às transformações decorrentes da redefinição do papel e das estruturas estatais e a possibilidade de novas formas organizacionais e institucionais em âmbitos territoriais e sociais diversos dos tradicionalmente predominantes. Assim, inicia-se a discussão a partir da noção de governança e governança global, as questões dos atores e sua legitimidade. Em seguida, ao longo de um percurso que parte do realismo das Relações Internacionais, para constatar sua impossibilidade de explicar a institucionalização e jurificação internacionais ou globais, seguindo por elaborações como o neoliberalismo institucionalista, o neorealismo e o construtivismo para estabelecer pontos de vista complementares, embora tensionados, a partir dos quais se pode tecer uma imagem complexa e reveladora de temas atuais.

Ao escapar dos lugares comuns tão frequentes no discurso da globalização, os autores abrem novas perspectivas para o estudioso ou o leitor interessado em temas internacionais. As mais diversas categorias de análise, apresentadas em linguagem precisa e agradável, se mostram essenciais para abrir novas perspectivas de análise e, o que talvez seja até mesmo mais importante, possibilita um tratamento teoricamente adequado que se mostra capaz de articular os vários aspectos de uma questão concreta posta em tela com as vicissitudes da internacionalidade.

Elaboram-se, com esse fim, conceitos capazes de orientar estratégias de estudo que mesclam uma abordagem estrutural com a compreensão cultural e construtivista. Da primeira perspectiva, característica do realismo e do neoliberalismo das Relações Internacionais, por exemplo, observa-se a possibilidade de generalizar e identificar regularidades a partir de variáveis presentes em várias situações e temáticas, as quais podem ser expressas em questões como: Quantos países estão envolvidos? Qual o poder relativo de cada um deles? Trata-se de temática essencial para a segurança (Estados refratários à participação de outros atores) ou de outra natureza (maior permeabilidade)? Já existe uma organização internacional ou tratados a respeito do tema?

Do outro ponto de vista, ganha corpo a importância da construção conjunta de identidades e sentidos a partir da interação entre Estados, com ou sem a participação de outros atores relevantes (ONGs, empresas multinacionais, partidos, sindicatos e comunidades epistêmicas, entre outros). Mais do que a avaliação e análise a partir dos elementos estruturais, busca-se compreender a importância da história e cultura resultante das efetivas relações.

Uma pausa para reflexão: como a questão que se tem em mente se coloca em face destes elementos de análise? O ecoturismo - e seus efeitos para a sustentabilidade e proteção ambiental - é um tema fortemente atrelado à segurança? Quais são os Estados interessados no funcionamento de esquemas de governança ou regimes internacionais nessa matéria? Eles estão agrupados em função de seus interesses (por exemplo, forne- 
cedores e consumidores do serviço)? Há uma potência hegemônica? Há organizações internacionais sobre o tema? Há tratados internacionais a respeito? Há regras sugeridas por outros atores? Elas são seguidas? Como se articulou, historicamente, o discurso da proteção ambiental vinculada ao uso econômico de recursos ambientais? Há grupos de atores articulados, efetivamente, em torno de interesses e posições a respeito do tema?

Ora, não é difícil de notar que, assim, se vai além dos lugares comuns. A problemática se desloca para uma avaliação prática das ações possíveis, para a influência sobre os processos informados de tomada de decisão que, em face de ambientes concretos, mas em constante movimento, são capazes de estabelecer estratégias efetivas. $\mathrm{O}$ que é melhor? Isso ou aportar a moderníssima perspectiva crítica conforme a qual a globalização destrói os atores coletivos e favorece o capital? Enfrentar as questões ou recoIher-se ao conforto do abrigo de opiniões como "é simples demais para ser discutido, pois basta por na conta do mercado" ou "é complexo demais para ser discutido, pois é preciso considerar todo e cada detalhe desde a perspectiva específica de todo e cada ator"?

As respostas podem variar, é claro. Fácil saber o que é fácil... É bem mais difícil compreender efetivamente os processos relevantes e, neste sentido, o livro analisado se apresenta como um instrumento útil, senão necessário. Tê-lo disponível é, decerto, uma vantagem para muitos pesquisadores, especialmente os interessados em gerar estudos e reflexões que venham a fazer diferença no tratamento de questões e problemas que já não podem ser confinados aos limites territoriais dos Estados.

Fernanda Sola: Universidade Federal de São Carlos, Sorocaba, SP, Brasil. Email: fernandasola@hotmail.com

Link para o currículo Lattes: http://lattes.cnpq.br/2265749626773521

Data de submissão: 11 de setembro de 2012

Data de recebimento de correções: 20 de setembro de 2012

Data do aceite: 26 de setembro de 2012

Avaliado anonimamente 